\title{
Seasonal Impact on Ovulatory and Fertility Responses Following Presynch-Heatsynch and Heatsynch Treatments in Buffaloes
}

\author{
Harmeet Singh Sandhu*, S. S. Dhindsa, M. Honparkhe and Prahlad Singh \\ Department of Veterinary Gynaecology and Obstetrics, Guru Angad Dev Veterinary and \\ Animal Sciences University, Ludhiana, India-141004 \\ *Corresponding author
}

\section{A B S T R A C T}

\begin{tabular}{l} 
K e y w o r d s \\
Buffalo, Estrus \\
synchronization, \\
Season, Heatsynch, \\
Presynch- \\
Heatsynch \\
\hline Article Info \\
$\begin{array}{l}\text { Accepted: } \\
\text { 05 April } 2020 \\
\text { Available Online: } \\
\text { 10 May } 2020\end{array}$ \\
\hline
\end{tabular}

The reproductive ability of buffalo is reduced during summer season. The present study was conducted on 60 postpartum cyclic buffaloes ( $>45$ days in milk) to assess the ovarian activity and fertility rate following modified Heatsynch protocol. The study was conducted during summer (May-July, $n=30$ ) and winter (December-February, $n=30$ ) seasons. In group I, a PGF2 $\alpha$ (Cloprostenol, $500 \mathrm{mcg}$ ) was administered on day $-14,-2$ and 7 . A gonadotropin releasing hormone ( $\mathrm{GnRH}$ : Buserlin acetate, $10 \mathrm{mcg}$ ) was administered on day 0 and estradiol (Estradiol benzoate, $1 \mathrm{mg}$ ) on day 8 followed by timed artificial insemination (TAI) $48 \mathrm{~h}$ later on day 10. In group II, first 2 PGF2 $\alpha$ injections were not administered; however, rest of the treatment was similar to group I. The ovulatory response following estradiol benzoate administration was comparable in both groups during summer (86.66 vs. $80.00 \%$ in group I and II, respectively) and winter (100.00 vs. $100.00 \%$ in group I and II, respectively) seasons. However, conception rate was on higher side in group I $(60.00 \%)$ compared to group II $(26.66 \%)$ buffaloes in summer season. In winter season conception rate was 73.33 and 53.33 percent in group I and II, respectively. The present findings indicated that Presynch-Heatsynch treatment may increase the conception rate in buffaloes during summer season as compared to Heatsynch treatment.

\section{Introduction}

The factors affecting postpartum pregnancy rate in buffaloes are cyclicity, heat stress, energy balance, parity, milk production, diet, and diseases (Moreira et al., 2001; Santos et al., 2004). The expression of decreased estrus behaviour is mainly associated with heat stress in bovine resulting in higher percentage of undetected estrus (Thatcher and Collier,
1986). Subsequently, there is a reduction in the number of inseminations and an increase in the proportion of inseminations that do not result in pregnancy (Hansen, 1997).

The heat stress causes decrease in steroid hormone production which alters the follicular development and oocyte growth (Wolfenson et al., 1997). The dominant follicle growth is also reduced by heat stress 
resulting in incomplete dominance that increases the growth of subordinate follicles (Wolfenson et al., 1995). Thus, the duration of dominant follicle is increased in summer which is negatively correlated with fertility (Mihm et al., 1994). The heat stress results in altered circulation and nutritive supply to the uterus and ovaries causing impairment in normal physiology.

To maintain a calving interval of $13-14$ months, successful breeding must take place within 85 - 115 days after parturition in buffaloes, unfortunately that seldom occurs in Indian conditions. Buffaloes are sexually activated by decreased day length and temperature. In winter the breeding frequency of buffaloes is highest and in the summer season it is lowest (Zicarelli, 2010). In general, buffaloes show estrus signs during early hours and late hours of the day with a peak of about $37 \%$ in early morning. The incidence of anestrus varies between 20-80\% in buffaloes depending on season. Maximum percentage of buffaloes exhibit postpartum estrus during the month of September followed by October and minimum during April and May due to high maximum air temperature (Abayawansa et al., 2011). The conception rate is also affected due to environmental temperature variations. The threshold thermal heat index (THI) for conception rate has been identified as 75 and above that threshold; the decline in overall conception rate occurs (Dash, 2013).

Estrus synchronization is considered a great tool to induce estrus and ovulation in buffaloes. Timed artificial insemination (TAI) protocol is an effective planned breeding program, developed in lactating dairy animals, that allows AI without estrus detection (Pursley et al., 1995; Pursley et al., 1997). Many protocols have been developed and tested in buffaloes with variable success. The protocols involving estradiol are considered comparatively better than the others due to higher tendency of estrogens in inducing estrus behaviour in buffaloes (Sandhu et al., 2017). As buffalo reproduction can be greatly influenced by altered ambient temperature, the current study was conducted to evaluate seasonal impact on ovulatory and fertility responses following PresynchHeatsynch and Heatsynch protocols in buffaloes.

\section{Materials and Methods}

The study was carried out on 60 post-partum cyclic buffaloes (> 45 days post calving) maintained at dairy farm, Directorate of Livestock Farms, Guru Angad Dev Veterinary and Animal Sciences University, Ludhiana, Punjab, India. The selected buffaloes had BCS 2.5 to 4 on a scale of 1 to 5 basis (Edmondson et al., 1989). The animals were in 2nd to 6th lactations and had a body weight ranging from $400-650 \mathrm{~kg}$. All the animals were kept under loose housing system. Only buffaloes that were in general good health and free from genital abnormalities were included. The cyclic status of all buffaloes was assessed by transrectal ultrasonographical examination of ovarian structures at the start of the study and only those buffaloes that had a CL on either of the two ovaries were included in the study.

\section{Experimental Design}

The 30 no. of buffaloes were taken in summer season (May-July) and another 30 buffaloes in winter season (December-February). A modified Heatsynch protocol was applied to animals in group I and other buffaloes were subjected to Heatsynch protocol (Group II). The study was conducted in 4 replicates. The first two replicates were performed in summer (May-July) and another two in winter (December- February). In replicate $1 \mathrm{st}(\mathrm{n}=15$, group $\mathrm{I}=08$; group $\mathrm{II}=07$ ), replicate 2 nd 
( $\mathrm{n}=15$, group $\mathrm{I}=07$; group $\mathrm{II}=08)$, replicate 3 rd $(n=15$, group $I=08$; group $I I=07)$, replicate 4 th $(\mathrm{n}=15$, group $\mathrm{I}=07$; group $\mathrm{II}=08)$.

In group-I, on day -14 and -2 , each buffalo was administered PGF2 $\alpha$ analogue (Cloprostenol, $500 \mathrm{mcg}$, IM). On day 0, Gonadotropin releasing hormone analogue (GnRH: Buserelin acetate, 10mcg, IM) was administered. On day 7, all buffaloes were administered PGF2 $\alpha$ analogue (Cloprostenol, $500 \mathrm{mcg}$, IM). On day 8, estradiol benzoate analogue (estradiol benzoate, $1 \mathrm{mg}$, IM) was administered followed by FTAI $48 \mathrm{~h}$ later on day 10. In group-II, first two injections (on day -14 and -2) were not given and rest of the treatment was same as explained in group I. All buffaloes of both groups were subjected to blood sampling and transrectal ultrasonographic examination of ovarian structures on the days mentioned in Fig. 1.

\section{Results and Discussion}

The ovulatory responses and first AI conception rates following PresynchHeatsynch and Heatsynch treatments in buffaloes have been presented in Table 1. Our hypothesis was that presynchronization before Heatsynch might improve conception rate during low breeding (summer) season. Thus, seasonal variability in terms of ovulatory and conception rates in buffaloes subjected to Presynch-Heatsynch and Heatsynch treatments was analysed in the present study. Further, follicle size was also measured by ultrasonography to assess dominance and ovulation. Follicular wave in buffaloes is characterized by the presence of small follicles $(\geq 3 \mathrm{~mm})$ that use to emerge together and develop upto 5-7 $\mathrm{mm}$ in diameter. Small follicles of $\sim 4 \mathrm{~mm}$ diameter enter a common growth phase during each follicular wave and one follicle of the group grows rapidly to attain ovulatory size (Ginther et al., 2003) by suppressing the growth of other subordinate follicles and preventing emergence of a new follicular wave (Armstrong and Webb, 1997). In current study irrespective of the season, the mean diameter of dominant follicle (DF) on day -2 and 0 remained significantly larger $(\mathrm{P}<0.05)$ in group I compared to II $(7.44 \pm 0.14$ and $9.09 \pm 0.31$ vs. $6.47 \pm 0.26$ and $8.02 \pm 0.30$ $\mathrm{mm}$, respectively). The observations indicated favourable effect of presynchronization in group I animals. Administration of PGF $2 \alpha$ before first $\mathrm{GnRH}$ injection of any $\mathrm{GnRH}$ based treatment enhances pituitary release of luteinizing hormone (LH) in response to GnRH (Mirmahmoudi et al., 2014).

Further, DF diameter remained significantly higher on the day of estradiol benzoate (EB) injection $(\mathrm{P}<0.05)$ and FTAI $(\mathrm{P}<0.01)$ in group I $(12.82 \pm 0.18$ and $15.04 \pm 0.35 \mathrm{~mm}$, respectively) compared to group II $(11.19 \pm 0.42$ and $12.81 \pm 0.31 \mathrm{~mm}$, respectively). It has been established that if animals ovulate after first GnRH injection, they are more likely to have functional DF capable of ovulation after final $\mathrm{GnRH}$ injection of $\mathrm{GnRH}$ based protocol (Vasconcelos et al., 1999). Within each group, size of DF during second follicular wave that emerged after induction of ovulation by GnRH injection on day 0 , increased significantly $(\mathrm{P}<0.05)$ after administration of PG on day 7 by the time of AI in both groups (Group I: $10.21 \pm 0.25$ to $15.04 \pm 0.35$; Group II: $10.01 \pm 0.29$ to 12.81 $\pm 0.31 \mathrm{~mm}$, respectively).

The estradiol concentrations were significantly increased $(\mathrm{P}<0.05)$ on the day of TAI $(46.06 \pm 1.53$ and $39.91 \pm 1.95 \mathrm{pg} / \mathrm{ml}$ in Presynch-heatsynch and heatsynch groups, respectively). The present findings were in corroboration with the earlier report by Batra and Pandey (1982) who reported that estradiol concentration increases to $45-50 \mathrm{pg} / \mathrm{ml}$ at the time of estrus. Buffalo is often considered as seasonal breeder with reduced estrus intensity 
and pregnancy rates during hot summer months (Mohan et al., 2009). Silent estrus is perhaps the most important factor leading to poor reproductive efficiency in buffaloes (Prakash et al., 2002). Moreover, estradiol production by granulosa cells remains high in winter and autumn compared to summer (Wolfenson et al., 1997).

The ovulatory response following EB was comparable in both groups during summer (86.66 vs. $80.00 \%$ in group I and II, respectively) and winter (100.00 vs. $100.00 \%$ in group I and II, respectively) seasons. The most important finding of current study was observation of higher conception rate in group I $(60.00 \%)$ compared to group II $(26.66 \%)$ buffaloes during summer season. In winter season, conception rate was 73.33 and 53.33 percent in group I and II, respectively.
The exposure of the DF to high progesterone $\left(\mathrm{P}_{4}\right)$ environment in Presynch-Heatsynch group might have improved the quality of oocyte and subsequent pregnancy rate following TAI in buffaloes.

This finding was supported by the observation of larger $(\mathrm{P}<0.01)$ pre-ovulatory $\mathrm{DF}$ size in buffaloes subjected to Presynch-Heatsynch compared to Heatsynch treatment $(15.04 \pm 0.35$ $\mathrm{v} / \mathrm{s} 12.81 \pm 0.31$, respectively). It is believed that higher $\mathrm{P}_{4}$ during growth of ovulatory follicles leads to more than 10 percent improvement in pregnancy rate following TAI (Bisinotto et al., 2010). The possible mechanism by which low concentration of $\mathrm{P}_{4}$ reduces fertilization and/or reduce embryo survival rates include effects on oocyte quality or alteration in oviductal and uterine environment (Inskeep, 2004).

Table.1 Influence of season on ovulatory and fertility responses following PresynchHeatsynch and Heatsynch treatments in buffaloes

\begin{tabular}{|l|c|c|}
\hline \multicolumn{1}{|c|}{ Treatment } & $\begin{array}{c}\text { Percent of ovulatory response } \\
\text { (Number of buffaloes/Total } \\
\text { number of buffaloes) }\end{array}$ & $\begin{array}{c}\text { Conception } \\
\text { rate (\%) }\end{array}$ \\
\hline \multicolumn{2}{|c|}{$\begin{array}{c}\text { Summer (May-July) } \\
\text { Presynch-Heatsynch }(\mathbf{n = 1 5})\end{array}$} & $86.66(13 / 15)$ \\
\hline Heatsynch $(\mathbf{n = 1 5})$ & $80.00(12 / 15)$ & $60.00(9 / 15)$ \\
\hline \multicolumn{2}{|c|}{ Winter (December-February) } \\
\hline Presynch-Heatsynch $(\mathbf{n = 1 5 )}$ & $100.00(15 / 15)$ & $73.33(11 / 15)$ \\
\hline Heatsynch $(\mathbf{n = 1 5})$ & $100.00(15 / 15)$ & $53.33(8 / 15)$ \\
\hline
\end{tabular}

Figures in parenthesis indicate number of animals

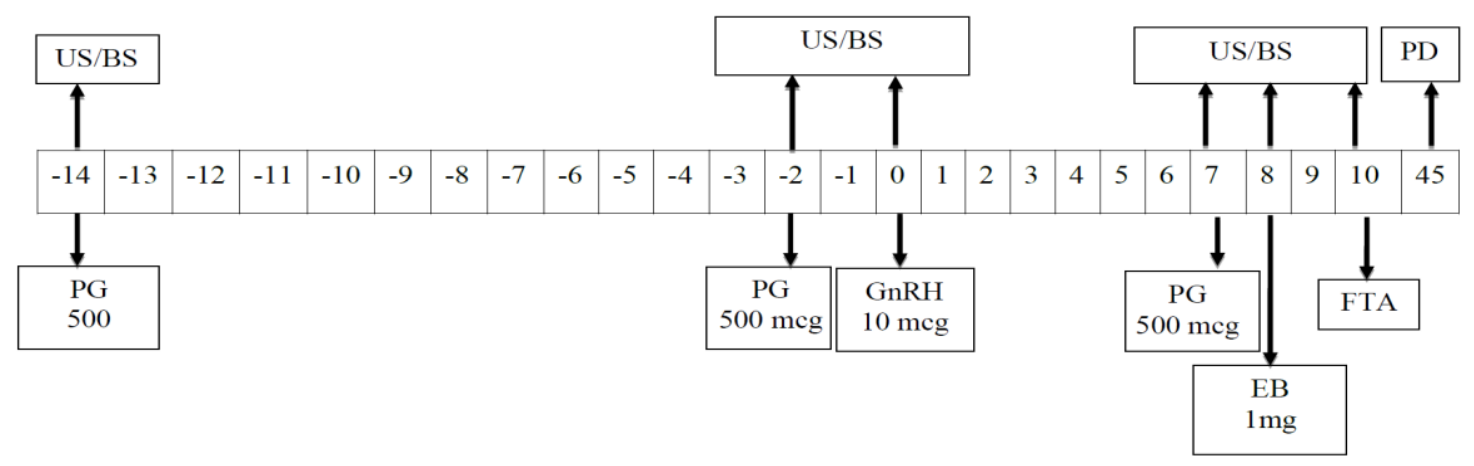

GROUP I $(n=30)$ 


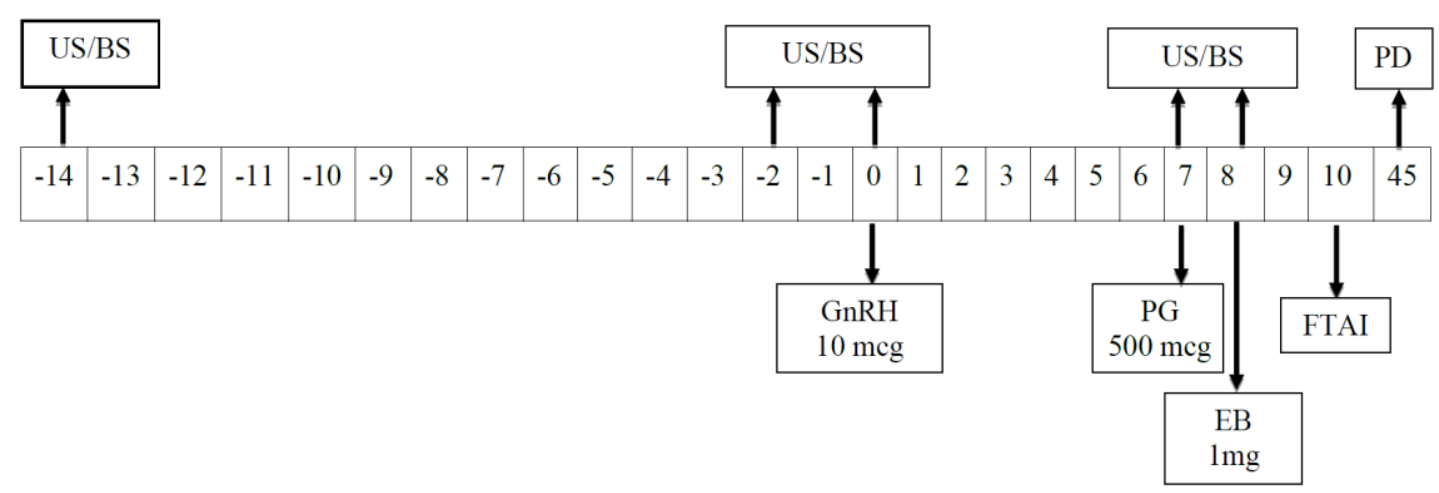

GROUP II $(n=30)$

Fig.1 Estradiol based estrus synchronization protocols for fixed timed artificial insemination in buffaloes

PG- Prostaglandin $\mathrm{F}_{2} \alpha$; GnRH- Gonadotrophin Releasing Hormone; EB-Estradiol Benzoate; BS-Blood Sample; US- Ultrasound Examination; AI- Artificial Insemination

The reproductive efficiency of buffalo is impaired by poor estrus expression and low conceptions during summer season due to intense heat stress leading to prolonged calving intervals. The TAI protocols involving estradiol are preferred in summer months due to promising effect of estradiol on estrus expression and LH surge that helps improve buffalo fertility.

The present study findings indicated that ovulatory and pregnancy rates could be improved by incorporation of presynchronization prior to administration of Heatsynch protocol during summer season in buffaloes. Thus, Presynch-Heatsynch protocol may successfully be used to improve conception rate in buffaloes during summer season.

\section{References}

Abayawansa, W.D., Prabhakar, S., Singh A.K., Brar, P.S. 2011. Effect of climatic changes on reproductive performance of Murrah buffaloes in Punjab: A retrospective analysis. Indian J Anim Sci. 81(4): 334-339.

Armstrong, D. G., and Webb, R. 1997. Ovarian follicular dominance: the role of intraovarian growth factors and noval proteins. Review of
Reproduction 2: 139-46.

Batra, S.K., and Pandey, R.S. 1982/83. Luteinizing hormone and oestradiol-17 $\beta$ in blood plasma and milk during oestrous cycle and early pregnancy in Murrah buffaloes. Anim. Reprod. Sci. 5: 247-57.

Bisinotto, R.S., Chebel, R.C., and Santos, J.E., 2010. Follicular wave of the ovulatory follicle and not cyclic status influences fertility of dairy cows. J. Dairy Sci. 93(8): 3578-87.

Dash, S. Genetic evaluation of fertility traits in relation to heat stress in Murrah buffaloes. 2013. M.V. Sc. Thesis, ICAR-NDRI (Deemed University), Karnal, Haryana, India.

Edmondson, A.J., Lean, I.J., Weaver, L.D., Farver, T., and Webster, G. 1989. A body condition scoring chart for Holstein dairy cows. J. Dairy Sci. 72: 68-78.

Ginther, O.J., Beg, M.A., Donadeu, F.X., and Bergfelt, D.R. 2003. Mechanism of follicle deviation in monovular farm species. Anim. Reprod. Sci. 78: 239-57.

Hansen, P.J. 1997. Effects of Environment on Bovine Reproduction. In: Current Therapy in Large Animal Theriogenology (Eds.) R.S., Youngquist, W.B., Saunders and P.A., Philadelphia. Pp 403-415.

Inskeep, E.K. 2004. Preovulatory, postovulatory and postmaternal recognition effects of concentrations of progesterone on embryonic survival in the cow. J. Anim. Sci. 82 (Supple 


\section{3): E24-E39.}

Mihm, M., Baguisi, A., Boland, M.O., and Roche, J.F. 1994. Association Between the Duration of Dominance of the Ovulatory Follicle and Pregnancy Rate in Beef Heifers. J. Reprod. Fertil. 102: 123-130.

Mirmahmoudi, R., and Prakash, B. S. 2014. Temporal changes in endogenous estrogens and expression of behaviors associated with estrus during the periovulatory period in doublesynch treated Murrah buffaloes (Bubalus bubalis). Iran. J. Appl. Anim. Sci. 4(3): 499-504.

Mohan, K., Sarkar, M., and Prakash, B.S. 2009. Efficiency of Heatsynch protocol in estrus synchronization, ovulation and conception of dairy buffaloes (Bubalus bubalis). AsianAustralas J Anim Sci 22(6): 774-80.

Moreira, F., Orlandi, C., Risco, C.A., Mattos, R., Lopes, F. and Thatcher, W.W. 2001. Effects of Presynchronization and Bovine Somatotropin on Pregnancy Rates to a Time Artificial Insemination Protocol in Lactating Dairy Cows. J. Dairy. Sci. 84: 1646-1659.

Prakash, B.S, Paul, V., and Anandlaxmi, N., 2002. Development and validation of a simple, sensitive, second antibody format enyzme immunoassay for $\mathrm{LH}$ determination in plasma. J. Immunol. Methods 270: 281-90.

Pursley, J. R., Mee, M. O., and Wiltbank, M. C. 1995. Synchronization of Ovulation in Dairy Cows Using PGF2 $\alpha$ and GnRH. Theriogenology 44: 915-923.

Pursley, J.R., Wiltbank, M.C., Stevenson, J.S., Ottobre, J.S., Garverick, H.A. and Anderson, L.L. 1997. Pregnancy Rates per Artificial Insemination for Cows and Heifers Inseminated at a Synchronized Ovulation or Synchronized Estrus. J. Dairy Sci. 80:295300.

Sandhu H.S., Dhindsa S.S., Honparkhe M., Singh
Bilawal, Singhal S., and Jindal R. 2017 Relationship between Estrus Signs and Subsequent Fertility Rates in Buffaloes Subjected to Estradiol based Synchronization Treatments. Theriogenology Insight: 7(3): 15.

Santos, J.E.P., Juchem, S.O., Cerri, R.L.A., Galvão, K.N., Chebel, R.C., Thatcher, W.W., Dei, C.S. and Bilby, C.R. 2004. Effect of Bovine Somatotropin and Reproductive Management on Reproductive and Lactational Performance of Holstein Dairy Cows. J. Dairy Sci. 87: 868-881.

Thatcher, W.W., and Collier, R.J. 1986. Effects of Climate on Bovine Reproduction. In: Current Therapy in Theriogenology 2 (Eds.) D.A. Morrow, W.B. Saunders, P.A. Philadelphia. Pp. 301-309.

Vasconcelos, J.L.M., Silcox, R.W., Rosa G.J.M., Pursley, J.R., and Wiltbank, M.C. 1999. Synchronization rate, size of the ovulatory follicle, and pregnancy rate after synchronization of ovulation beginning on different days of the estrous cycle in lactating dairy cows. Theriogenology 52(6): 1067-78.

Wolfenson, D., Lew, B.J., Thatcher, W.W., Graber, Y., and MedanLew, R. 1997. Seasonal and Acute Heat Stress Effects on Steroid Production by Dominant Follicles in Cows. Anim. Reprod. Sci., 47: 9-19.

Wolfenson, D., Thatcher, W.W., Badinga, L., Savio, J. D., MedanLew, R. B. J., Braw-Tal, R. and Berman, A. 1995. Effect of Heat Stress on Follicular Development During the Estrous Cycle in Lactating Dairy Cattle. Biol. Reprod. 52: 1106-1113.

Zicarelli, L. 2010. Enhancing reproductive performance in domestic dairy water buffalo (Bubalus bubalis). Soc. Reprod. Fertil. Suppl. 67:443-455.

\section{How to cite this article:}

Harmeet Singh Sandhu, S. S. Dhindsa, M. Honparkhe and Prahlad Singh. 2020. Seasonal Impact on Ovulatory and Fertility Responses Following Presynch-Heatsynch and Heatsynch Treatments in Buffaloes. Int.J.Curr.Microbiol.App.Sci. 9(05): 340-345.

doi: https://doi.org/10.20546/ijcmas.2020.905.037 